\title{
ESTADO, EDUCAÇÃO E PLANEJAMENTO EDUCACIONAL: ENTRELAÇAMENTOS TEÓRICO-PRÁTICOS ${ }^{1}$
}

\author{
Natália Ayres ${ }^{2}$ \\ Raquel Dias Araújo ${ }^{3}$ \\ Eduardo Ferreira Chagas ${ }^{4}$
}

\begin{abstract}
Resumo:
O planejamento, atividade especificamente humana, constitui uma ação intencional para alcançar determinados fins. $\mathrm{O}$ ato de planejar está presente na vida individual e social, a partir do qual se projetam escolhas e finalidades. No âmbito do Estado, o planejamento consiste em uma forma de intervenção e controle. Nesse sentido, o planejamento educacional remete a uma forma de intervenção do Estado em educação, para o cumprimento de determinadas funções, considerando aspectos econômicos, políticos e sociais. Em relação às funções atribuídas à escola, podemos destacar a formação voltada para a aquisição mínima de competências e valores, que visam à adequação dos indivíduos à sociedade capitalista. $\mathrm{O}$ planejamento da educação, situado em um contexto histórico, corresponde a determinadas concepções de sociedade, ser humano e educação. O planejamento, como parte da política educacional, não pode ser entendido como uma ação neutra, pois não se trata meramente de aspectos técnicos, mas, sobretudo, de uma ação política articulada com os interesses dominantes. Intentamos, com este trabalho, situar o papel do Estado na elaboração do planejamento educacional no Brasil, abordando as diferentes concepções e os tipos de planejamento educacional, bem como o Plano Nacional de Educação, no sentido de buscar identificar quais as contradições e as implicações em torno da construção de uma educação pública, gratuita e de qualidade.
\end{abstract}

Palavras-chave: Planejamento Educacional. Educação. Estado.

\section{STATE, EDUCATION AND EDUCATIONAL PLANNING: THEORETICAL- PRACTICAL INTERLACTIONS}

\begin{abstract}
:
The planning, the human activity, the intentional action to achieve the set goals. The act of planning is present in the individual and social life, from which type of project choices and purposes. At the state level, planning consists of a form of intervention and control. In this sense, educational planning removes a form of state intervention in education, to fulfill the functions, considering the economic, political and social aspects. Regarding the functions assigned to the school, we can highlight the training aimed at the acquisition of minimum skills and values, aimed at the adaptation of individuals to capitalist society. The planning of education, situated in the historical context, corresponds to the conceptions of society, human being and education. Planning, as part of educational policy, cannot be carried out as a neutral action, as it does not merely deal with technical aspects, but mainly a political action articulated with the dominant interests. With this work, we intend, the place or role of the State in which the educational planning in Brazil, approaching as different conceptions and the types of educational planning, as well as the National Education Plan, without the sense of trying to identify what are the contradictions and the implications for building a free and quality public education.
\end{abstract}

Keywords: Educational Planning. Education. State.

1 Artigo escrito a partir do trabalho Planejamento educacional: concepções, plano nacional de educação e implicações para a educação brasileira, publicado nos Anais da III Semana de Economia Política, ocorrida em 2016, na Universidade Federal do Ceará (UFC).

2 Doutoranda em Educação Brasileira pela Universidade Federal do Ceará (UFC). Professora do Instituto Federal de Educação, Ciência e Tecnologia do Ceará (IFCE). Email: natalia_ayres@yahoo.com.br.

3 Doutora em Educação pela Universidade Federal do Ceará (UFC). Professora Associada do Curso de Pedagogia da Universidade Estadual do Ceará (UECE). Email: raquel.dias69@ gmail.com.

4 Doutor em Filosofia pela Universidade Alemã de Kassel. Professor de Graduação e Pós-Graduação do Curso de Filosofia da Universidade Federal do Ceará (UFC). Colaborador do Programa de PósGraduação da Faculdade de Educação (FACED) da UFC e Colaborador do Programa de PósGraduação do Mestrado Acadêmico em Filosofia da Universidade Estadual do Ceará (UECE). Bolsista do CNPQ. E-mail: ef.chagas@uol.com.br. 


\section{Introdução}

Este artigo tem por objetivo situar o papel do Estado na elaboração do planejamento educacional no Brasil, abordando as diferentes concepções e os tipos de planejamento, bem como o Plano Nacional de Educação, no sentido de buscar identificar desafios e possibilidades para a construção de condições de concretização de uma educação pública pautada na necessidade de corrigir o déficit educacional historicamente acumulado. Com base nesse intento, organizamos a exposição em cinco momentos, incluindo as considerações finais: 1) reflexão crítica acerca do planejamento educacional, situando o papel do Estado na sua elaboração e as finalidades estabelecidas; 2) apresentação de diferentes concepções e tipos de planejamento educacional; 3) explicitação do planejamento da educação na Lei de Diretrizes e Bases da Educação Nacional - 9.394/96 (LDB); 4) apontamentos sobre o Plano Nacional de Educação; e 5) considerações sobre as contradições e as implicações em torno da construção de uma educação pública, gratuita e de qualidade.

\section{Quem e para que se planeja a educação?}

Procuramos exprimir aqui, com base nas questões anunciadas no título deste item, a definição de planejamento educacional e suas finalidades. Segundo Horta (1985), o planejamento educacional consiste em uma forma de intervenção do Estado, especificamente na educação, relacionada, de maneira diversa e historicamente situada, com outros modos de o Estado intervir na educação, por exemplo, por meio da legislação educacional.

Vale destacar que o Estado não é uma instância neutra, capaz de estabelecer a unidade entre os diferentes interesses da sociedade. Para Marx e Engels (2009, p. 38-9), o Estado, como instância de dominação, atende aos interesses da burguesia, porquanto não tem fins próprios nem universais.

[...] a burguesia, desde o estabelecimento da indústria moderna e do mercado mundial, conquistou para si mesma, no Estado representativo moderno, influência política exclusiva. O governo do Estado moderno não é senão um comitê para gerenciar os assuntos comuns de toda a burguesia.

\begin{tabular}{|l|l|l|l|l|}
\hline Q Povista Dialectus & Ano 9 & n. 16 & Janeiro-Abril 2020 & p. $100-112$ \\
\hline
\end{tabular}


Com suporte na concepção marxista de Estado, corroboramos a noção de que o Estado, ao implantar uma determinada política educacional, tem por finalidade "levar o sistema educacional a cumprir as funções que lhe são atribuídas enquanto instrumento deste mesmo Estado". (HORTA, 1985, p.195).

Nesse sentido, quais seriam essas funções? Para Mészáros (2005, p.35), a educação institucionalizada vem cumprindo com as funções de: 1) “[...] fornecer os conhecimentos e o pessoal necessário à máquina produtiva em expansão do sistema do capital" e 2) "[...] gerar e transmitir um quadro de valores que legitima os interesses dominantes". Essas funções visam à adequação dos indivíduos à realidade social e a reprodução da sociedade capitalista.

Retomando o fio da meada, podemos afirmar, então, que o Estado planeja a educação, através dos órgãos específicos, com a finalidade de implantar uma determinada política educacional. Como o Estado não é neutro, ou seja, é o Estado representativo dos interesses de uma parcela da sociedade, no caso, da burguesia, ao planejar a educação, faz isso de forma interessada. O que isto quer dizer? Que as políticas educacionais resultantes do planejamento estatal carregam intencionalidades, reveladas e veladas.

Podemos ilustrar, por exemplo, com a política educacional expressa na Lei $n^{\circ}$ 13.415/2017 que reformou o ensino médio. De acordo com o Ministério da Educação - MEC (2017), a referida reforma consiste numa

\footnotetext{
[...] mudança na estrutura do sistema atual do ensino médio. Trata-se de um instrumento fundamental para a melhoria da educação no país. Ao propor a flexibilização da grade curricular, o novo modelo permitirá que o estudante escolha a área de conhecimento para aprofundar seus estudos. A nova estrutura terá uma parte que será comum e obrigatória a todas as escolas (Base Nacional Comum Curricular) e outra parte flexível. Com isso, o ensino médio aproximará ainda mais a escola da realidade dos estudantes à luz das novas demandas profissionais do mercado de trabalho. E, sobretudo, permitirá que cada um siga o caminho de suas vocações e sonhos, seja para seguir os estudos no nível superior, seja para entrar no mundo do trabalho (grifos nossos).
}

O objetivo da reforma, segundo o MEC, portanto, é melhorar a educação no país e flexibilizar o ensino médio. No entanto, faz isso por meio da profissionalização forçada e precoce dos jovens estudantes do ensino médio, quando tornam obrigatórias apenas as disciplinas português e matemática e oferece a "formação técnica e

\begin{tabular}{|l|l|l|l|l|}
\hline Q Povista Dialectus & Ano 9 & n. 16 & Janeiro - Abril 2020 & p. $100-112$ \\
\hline
\end{tabular}


profissional" dentre as opções de formação de aprofundamento acadêmico. Num contexto de crise, desemprego, incertezas, os jovens irão optar por história, geografia, filosofia, sociologia ou formação técnica e profissional?

Nesse sentido, a reforma do ensino médio está em fina sintonia com as funções do sistema educacional estabelecidas pelo Estado, ou seja, formar mão de obra e reproduzir a ideologia dominante.

É importante ressaltar que nada disso é realizado sem contradições. Há questionamentos, resistências, conflitos que envolvem todo o processo de planejamento e definição das políticas educacionais, refletindo em certa medida os diferentes interesses de classe.

\section{Diferentes concepções e tipos de planejamento educacional}

Expusemos no item anterior que, por intermédio do planejamento e de outras formas de intervenção, o Estado interfere na educação, a fim de que esta cumpra determinadas funções. Para Vieira e Albuquerque (2001, p.33), o planejamento educacional, atividade própria do governo, é inseparável da política, resultando em uma “complexa relação que se estabelece entre sociedade política (governo) e sociedade civil (forças sociais)".

As autoras, no livro Política e planejamento educacional, analisam diferentes concepções de planejamento: Planejamento Normativo Tradicional - PNT; Planejamento Estratégico - PE; Planejamento Participativo - PP e Planejamento do Gerenciamento da Qualidade Total - PGQT. Vejamos a descrição de cada uma delas.

O Planejamento Normativo Tradicional - PNT apresenta a ideia de que, para planejar, basta repetir comportamentos bem-sucedidos e reproduzir normas, limitando-se, assim, a simples projeção quantitativa das tendências passadas. Surge no âmbito da Aliança para o Progresso e sua expansão remete à Conferência de representantes dos países latino-americanos, realizada em Punta del Este, em 1961.

No Brasil, o planejamento sistemático passou a fazer parte das políticas governamentais a partir da Segunda Guerra Mundial, sendo entendido, inicialmente, como uma técnica racionalizada de organização das informações. Somente no período da ditadura civil-militar, contudo, o planejamento passa a ser tomado como sistemática governamental, por via do Decreto-Lei $\mathrm{n}^{\circ}$ 200/67. Os diferentes instrumentos de

\begin{tabular}{|l|l|l|l|l|}
\hline Q Pevista Dialectus & Ano 9 & n. 16 & Janeiro-Abril 2020 & p. $100-112$ \\
\hline
\end{tabular}


planejamento governamental expressam essa formalização: plano geral de governo, programas setoriais e regionais de duração plurianual. Com isso, surgiram, por um lado, os Planos Nacionais de Desenvolvimento, e, por outro, os Planos Setoriais de Educação (VIEIRA; ALBUQUERQUE, 2001).

As outras concepções de planejamento aparecem, de acordo com as autoras, com o objetivo de superar o caráter tecnocrático do Planejamento Normativo Tradicional - PNT. O Planejamento Estratégico - PE apresenta como características: continuidade e sistematicidade; realização de análises macros (econômicas e políticas); previsão de futuros alternativos; utilização de métodos quantitativos e qualitativos e trato das incertezas. Há dois tipos de PE: 1) corporativo, centrado nas demandas da economia e voltado para as empresas ou corporações privadas, sendo indicado para as instituições públicas interessadas em participar do mercado, e 2) situacional, pensado para dirigentes políticos, por considerar não só as variáveis econômicas, mas políticas.

O Planejamento Participativo - PP tem origem nas elaborações da Equipe Latino-Americana de Planejamento - ELAP (Chile). Para os formuladores, permite conhecer a realidade por meio da ação e da reflexão. No âmbito da educação, as suas ideias foram, de certo modo, incorporadas pela política no final do período militar, na transição democrática. Vieira e Albuquerque (2001) acrescentam que os governos estabelecidos nesse momento de transição precisaram imprimir nos seus planos administrativos uma resposta à demanda social por participação. A transição democrática, contudo, vem marcada, por um lado, por esse cenário de exigência participativa, de uma agenda prioritária para a educação, e por outro, pelo questionamento do Estado como aquele que deve assegurar os direitos sociais, que se traduz em "enxugamento" do Estado e corte de gastos nos serviços públicos.

O Planejamento no Gerenciamento da Qualidade Total - PGQT, ao retomar elementos de distintas abordagens organizacionais, possui um caráter híbrido. A escola é entendida como uma organização, uma prestadora de serviço educacional, e, como tal, deve garantir a satisfação de todos: alunos, pais, professores, funcionários, entidade mantenedora/acionistas e comunidade (VIEIRA; ALBUQUERQUE, 2001).

A partir de 1990, as agendas internacionais passaram a indicar medidas a serem seguidas pelos países da América Latina e Caribe. O marco dessa ingerência dos organismos internacionais na educação é a Conferência Mundial de Educação para Todos, realizada em Jomtien (Tailândia), em 1990. Desde essa conferência, vários

\begin{tabular}{|c|c|c|c|c|}
\hline Q Rovista Qialectus & Ano 9 & n. 16 & Janeiro - Abril 2020 & p. $100-112$ \\
\hline
\end{tabular}


eventos se sucederam com o discurso central de universalização do ensino básico, produzindo documentos e campanhas direcionados para a reforma educacional. No plano da gestão, podemos destacar, entre os procedimentos que os países deveriam seguir, indicados na Carta de Jomtien: promover políticas de apoio no terreno econômico, social e cultural e mobilizar recursos financeiros, públicos, privados e voluntários (TORRES apud SHIROMA; MORAES; EVANGELISTA, 2011).

Ao analisar o documento Educación y conocimiento: eje de la transformación productiva con equidade (1992), da CEPAL (Comissão Econômica para a América Latina e Caribe), Shiroma, Moraes e Evangelista (2011, p.55) identificam a ênfase conferida à "necessidade de reformas administrativas que operassem uma transmutação do Estado administrador e provedor para um Estado avaliador, incentivador e gerador de políticas".

Podemos perceber, com suporte na apresentação desses diferentes tipos de planejamentos, que eles se situam em determinados contextos históricos e intentam responder a uma dada conjuntura econômica, social e política.

\section{O planejamento da educação na Lei de Diretrizes e Bases da Educação Nacional -}

\subsection{4/96 (LDB)}

$\mathrm{Na}$ LDB, podemos identificar, ao mesmo tempo, um processo de centralização na elaboração e na avaliação da política educacional e um processo de descentralização na sua execução.

Gentili (1998), ao discutir a política educacional sob o advento do neoliberalismo, afirma que estaria caracterizada por um duplo aspecto, a saber, de centralização do controle pedagógico, que se expressa na intervenção do Estado no planejamento e na definição da política educacional, como também por meio da intervenção na avaliação de externa e de larga escala, e, por outro lado, de descentralização dos mecanismos de financiamento e de gestão, implicando numa desresponsabilização do Estado com a tarefa de manter e desenvolver o sistema educacional.

Os seus Artigos $8^{\circ}$ e $9^{\circ}$ expressam que a União é responsável pela formulação, implementação, acompanhamento e avaliação da política educacional. É

\begin{tabular}{|l|l|l|l|l|}
\hline Q Pevista Dialectus & Ano 9 & n. 16 & Janeiro-Abril 2020 & p. $100-112$ \\
\hline
\end{tabular}


incumbência da União, em colaboração com os Estados, o Distrito Federal e os Municípios, a elaboração do Plano Nacional de Educação.

Aos Estados competem "elaborar e executar políticas e planos educacionais, em consonância com as diretrizes e planos nacionais de educação, integrando e coordenando as suas ações e as dos seus Municípios”. (BRASIL, 1996 - Art. 10).

Em relação aos municípios, a LDB estabelece que estes deverão "organizar, manter e desenvolver os órgãos e instituições oficiais de seus sistemas de ensino, integrando-os às políticas e aos planos educacionais da União e dos Estados”. (BRASIL, 1996 - Art. 11).

Apresentadas as incumbências das esferas governamentais no que diz respeito ao planejamento, perguntamos: qual o papel das escolas e dos docentes no planejamento da educação? A resposta fica restrita ao planejamento no interior da escola (planejamento escolar): para as instituições, "elaborar e executar sua proposta pedagógica" (BRASIL, 1996 - Art. 12), e, para os professores, "I. participar da elaboração da proposta pedagógica do estabelecimento de ensino" e "II. elaborar e cumprir plano de trabalho, segundo a proposta pedagógica do estabelecimento de ensino" (BRASIL, 1996 - Art. 13).

A forma que o planejamento assume nas escolas está intimamente relacionada à concepção e ao modelo de gestão educacional. No âmbito escolar, a atividade de planejar se expressa na elaboração da proposta pedagógica da escola, como previsto na $\mathrm{LDB}$, bem como na tarefa de preparação dos planos de aula das respectivas disciplinas e áreas do conhecimento. No entanto, tanto uma atividade quanto outra tem limites estabelecidos pela própria legislação e natureza do planejamento e da gestão.

Vimos no primeiro tópico do artigo que o Estado planeja a educação com a finalidade de implantar uma dada política educacional com objetivo de levar o sistema educacional a cumprir objetivos definidos pelo próprio Estado. Ora, a atividade de planejar a educação, como política global, que resulta em leis, projetos, programas, medidas etc. se dá no âmbito do Estado, enquanto aos estabelecimentos de ensino e aos docentes cabem planejar a operacionalização de suas ações delimitadas pelo currículo, pela avaliação externa, pelo financiamento etc.

Além desse limite, há outro que está relacionada à gestão. Embora a LDB, no Art. 14, determine que "Os sistemas de ensino definirão as normas da gestão democrática do ensino público na educação básica [...]”, a qual deve se efetivar por

\begin{tabular}{|l|l|l|l|l|}
\hline Q Pevista Dialectus & Ano 9 & n. 16 & Janeiro-Abril 2020 & p. $100-112$ \\
\hline
\end{tabular}


meio da "I - participação dos profissionais da educação na elaboração do projeto pedagógico da escola;", bem como da "II - participação das comunidades escolar e local em conselhos escolares ou equivalentes" (BRASIL, 1996), na prática, nem existe gestão democrática, nem efetiva participação dos profissionais da educação e da comunidade na definição do projeto pedagógico da escola, com raríssimas exceções.

\section{O Plano Nacional de Educação}

O Plano Nacional de Educação - PNE, previsto na LDB, é um plano global, que contém metas e estratégias para todos os níveis e modalidades de ensino, bem como para formação de professores, financiamento e outros aspectos da educação, tendo vigência de dez anos. Constitui, assim, um plano de Estado, pois “perpassa vários governos, os quais devem/deveriam elaborar seus planos de governos, isto é, planos de gestão, guardando fina sintonia com este". (ARAUJO; FARIAS; SOBRAL, 2013, p.2).

Vale lembrar que, para Saviani (1998), com qual temos total acordo, o PNE é a principal medida de política educacional decorrente da LDB.

Em 2001, no governo de Fernando Henrique Cardoso - FHC, foi aprovado o primeiro Plano Nacional de Educação com essa configuração, que teve vigência até 2011. As autoras destacam a disputa que se deu em torno de dois projetos de elaboração do PNE:

[...] Um, da chamada "sociedade brasileira" ou do Fórum Nacional em Defesa da Escola Pública que condensava a elaboração das entidades da classe trabalhadora, que independente e autonomamente, conseguiram produzir uma proposta alternativa de PNE condizente com os interesses dos trabalhadores e que assumia a defesa intransigente da educação pública. $\mathrm{O}$ outro era o projeto que expressava os interesses da iniciativa privada e que se encontrava em sintonia com as orientações de cunho neoliberal dos organismos internacionais. (ARAUJO; FARIAS; SOBRAL, 2013, p.2).

Como é sabido, o PNE aprovado expressou os interesses da iniciativa privada, seguindo as orientações neoliberais dos organismos internacionais. Um dos pontos mais questionados do Plano foi o veto de FHC para a meta de financiamento, prevista em 7\% do PIB. O PNE da "sociedade brasileira" indicava 10\%. O PNE (20012011), portanto, foi aprovado sem meta de financiamento, resultando no não cumprimento de $2 / 3$ das suas metas e sem aumento significativo do percentual do PIB

\begin{tabular}{|l|l|l|l|l|}
\hline Q Povista Dialectus & Ano 9 & n. 16 & Janeiro-Abril 2020 & p. $100-112$ \\
\hline
\end{tabular}


para a educação (a exigência, não concretizada, era somente para gasto no setor público).

O novo PNE (2014-2024) foi encaminhado no governo Lula, PL $n^{\circ}$ 8.035, e aprovado no governo Dilma, Lei $\mathrm{n}^{\circ}$ 13.005/2014, a qual determina no Art. 13, a construção do Sistema Nacional de Educação:

Art. 13. O poder público deverá instituir, em lei específica, contados 2 (dois) anos da publicação desta Lei, o Sistema Nacional de Educação, responsável pela articulação entre os sistemas de ensino, em regime de colaboração, para efetivação das diretrizes, metas e estratégias do Plano Nacional de Educação.

O Sistema Nacional de Educação consiste na organização da educação nacional sob bases e diretrizes comuns tomada como tarefa do Estado, a exemplo do que fizeram os países desenvolvidos nos séculos XIX e XX.

E o papel desses sistemas era precisamente universalizar a instrução pública, entendida como aquela que assegura, ao conjunto da população, o domínio da leitura, escrita e cálculo, ademais dos rudimentos das ciências naturais e sociais (história e geografia). Portanto, a referência fundamental da organização dos sistemas nacionais de ensino estava dada pela escola elementar que, uma vez universalizada, permitiria erradicar o analfabetismo. (SAVIANI, 2008, p. 7).

No Brasil, a educação só passou a ser discutida como uma questão nacional a partir da década de 1930 do século XX, mas nunca se constituiu o Sistema Nacional de Educação, o qual não poderia ser atribuição do PNE, ao contrário, a existência do Plano decorreria, pela lógica, da existência do Sistema. O PNE deveria ser um instrumento para concretização das tarefas do Sistema, como a universalização da educação básica.

Voltando ao Art. 13, vale registrar que até o presente momento não há qualquer iniciativa por parte do Poder Público que indique que a efetivação dessa medida.

No concernente à meta de financiamento, o novo PNE prevê a ampliação do “investimento público em educação pública de forma a atingir, no mínimo, o patamar de $7 \%$ (sete por cento) do Produto Interno Bruto - PIB do País no $5^{\circ}$ (quinto) ano de vigência desta Lei e, no mínimo, o equivalente a 10\% (dez por cento) do PIB ao final do decênio". Embora na redação da meta apareça "investimento público em educação

\begin{tabular}{|l|l|l|l|l|}
\hline Qevista Dialectus & Ano 9 & n. 16 & Janeiro-Abril 2020 & p. $100-112$ \\
\hline
\end{tabular}


pública", perde seu efeito quando encontramos no texto da Lei, no parágrafo $4^{\circ}$, do Artigo $5^{\circ}$, que o investimento público em educação engloba ainda os

[...] recursos aplicados nos programas de expansão da educação profissional e superior, inclusive na forma de incentivo e isenção fiscal, as bolsas de estudos concedidas no Brasil e no exterior, os subsídios concedidos em programas de financiamento estudantil e o financiamento de creches, préescolas e de educação especial na forma do art. 213 da Constituição Federal (BRASIL, 2014).

Os recursos públicos, portanto, serão destinados também para a iniciativa privada, contribuindo para a manutenção da grave crise pela qual passa a educação pública, visível na sua estrutura física, na falta de materiais, nas péssimas condições de trabalho, nos baixos salários dos trabalhadores da educação. Apesar da garantia do investimento equivalente a $10 \%$ do PIB ao final de vigência do PNE, Araújo, Rocha e Amâncio (2017, p. 198) ressaltam que

[...] o dispositivo presente no artigo $5^{\circ}$ parágrafo $4^{\circ}$, ao contabilizar os recursos das parcerias público-privadas, como Fies (Fundo de Financiamento Estudantil), Prouni (Programa Universidade para Todos) e Pronatec (Programa Nacional de Acesso ao Ensino Técnico e Emprego), como investimento público em educação, acaba por legitimar a transferência de dinheiro público para a iniciativa privada.

Vimos no item anterior que o planejamento, nos mais diversos âmbitos, tem relação estreita com a gestão educacional. Aqui, queremos destacar a sua ligação com o financiamento. Em última instância, que define o planejamento e ação resultante dele é a disponibilidade de recursos financeiros para este ou aquele fim. Saviani $(1998,125)$ deixa claro que, sob a determinação estrutural capitalista, independente da conjuntura, do matiz ideológico, do país, observa-se que a política social e a educacional, como modalidade desta, está subordinada à política econômica e, como consequência, “[...] do montante de recursos manipulados pelo poder público, a parcela destinada ao setor social tenderá ser sempre inferior àquelas destinadas aos demais setores”.

Em termos concretos, como essa relação entre planejamento e financiamento se revela? O PNE incorporou, com contradições, a reivindicação dos movimentos sociais relativa à elevação do percentual dos recursos aplicados na educação comparativamente ao PIB, ou seja, o Plano garantiu na meta 20 a aplicação de $10 \%$ do PIB na educação ao final da sua vigência. Em contrapartida, no final do ano de

\begin{tabular}{|l|l|l|l|l|}
\hline Q Povista Dialectus & Ano 9 & n. 16 & Janeiro-Abril 2020 & p. $100-112$ \\
\hline
\end{tabular}


2016, foi aprovada a Emenda Constitucional n ${ }^{\circ}$ 95/2016, que congela por 20 anos os investimentos em políticas públicas, incluindo a educação, com objetivo de garantir um superávit primário que será destinado ao pagamento da dívida pública. Nesse caso, a meta 20 do PNE fica totalmente comprometida, uma vez que o Brasil aplica, em média, 6\% do PIB. Como diz Saviani (1998), a política social subordina-se aos ditames da política econômica.

O planejamento da educação, especialmente, estará limitado, por 20 anos, ao teto dos gastos públicos.

\section{Considerações finais}

Para indicarmos as implicações para a educação, retomamos aqui desde o ponto de partida. O planejamento educacional, como uma forma de intervenção do Estado (capitalista), implica a implantação de determinadas políticas educacionais, a fim de que sejam cumpridas finalidades orientadas para a adequação dos indivíduos e a manutenção das condições existentes na sociedade do capital.

Em relação aos diferentes tipos e concepções de planejamento, apontamos: PNT: imposição de um padrão normativo e instrumental; Planejamento Estratégico: priorização da utilização eficiente dos recursos disponíveis; PGQT: responsabilização dos sujeitos pela qualidade da educação; Planejamento Participativo: Com a sua apropriação pelos governos, pode se expressar na centralização do planejamento e na descentralização da execução, esta, por sua vez, pode se traduzir em desresponsabilização por parte dos governos de garantir a educação pública. Isso se expressa na própria LDB, como retrocitado, a União, sobretudo, planeja e fixa as políticas, e as escolas executam.

Sobre o Plano Nacional de Educação, além da questão do financiamento, podemos mencionar o objetivo de instituir o Sistema Nacional de Educação, que poderia contribuir para a correção do déficit educacional historicamente acumulado. Para isso, entretanto, era necessário que a educação fosse tomada como prioridade, pois um dos principais obstáculos para a sua construção, como assevera Saviani (2014), é a histórica resistência à manutenção da educação pública no Brasil.

Compreendemos que a nossa atuação na educação pode contribuir para reproduzir as relações vigentes ou para caminhar no sentido da emancipação humana.

\begin{tabular}{|l|l|l|l|l|}
\hline Q Povista Dialectus & Ano 9 & n. 16 & Janeiro-Abril 2020 & p. $100-112$ \\
\hline
\end{tabular}


Nessa perspectiva, destacamos que devemos não apenas fazer denúncias, mas também exigências em torno da política educacional, por mais limitada que possa ser, articulando com as demandas mais gerais da classe trabalhadora.

\section{Referências}

ARAUJO, Raquel Dias; FARIAS, Paula Emanuela Lima de; SOBRAL, Karine Martins. O novo Plano Nacional de Educação (2011-2020) e a questão do financiamento público da educação. In: Anais da VI Jornada Internacional de Políticas Públicas. Maranhão: UFMA, 2013.

ARAUJO, Raquel Dias; AMANCIO, Nivânia Menezes; ROCHA, Antônia Rozimar Machado e. A questão do financiamento público da educação pública no novo Plano Nacional de Educação (2014-2024). In: ROCHA, Antônia Rozimar Machado e; ZIENTARSKI, Clarice; BASTOS, Remo Moreira Brito (Org.). Capitalismo contemporâneo e política educacional. Fortaleza: Nova Civilização, 2017.

BRASIL. Lei $\mathbf{n}^{\circ}$. 13.005, de 25 de junho de 2014. Aprova o Plano Nacional de Educação - PNE e dá outras providências. Brasília: DF, 2014. Disponível em: http://www.planalto.gov.br/ccivil_03/_ato2011-2014/2014/lei/113005.htm. Acesso em: 22/03/2017.

BRASIL. Lei no. 9.394/1996, de 20 de dezembro de 1996. Fixa as diretrizes e bases da educação nacional. Brasília: DF, 1996. Disponível em: http://www.planalto.gov.br/ccivil_03/leis/L9394.htm. Acesso em 22/03/2017.

BRASIL. Lei $\mathbf{N}^{\mathbf{1}} \mathbf{1 3 . 4 1 5 / 2 0 1 7}$, de 16 de fevereiro de 2017. Institui a Política de Fomento à Implementação de Escolas de Ensino Médio em Tempo Integral (Reforma do Ensino Médio). Brasília, DF, 2017. Disponível em: http://www.planalto.gov.br/ccivil_03/_ato2015-2018/2017/lei/L13415.htm. Acesso em: 22/03/2017.

GENTILI, Pablo. A falsificação do consenso: simulacro e imposição na reforma educacional do neoliberalismo. Petrópolis, RJ: Vozes, 1998.

HORTA, José Silvério Baia. Planejamento educacional. In: SAVIANI, Demerval et. al. Filosofia da educação. 2. ed. Rio de Janeiro: Civilização Brasileira, 1985.

MARX, Karl.; ENGELS, Friedrich. O manifesto do partido comunista. São Paulo: Editora Instituto José Luis e Rosa Sundermann, 2009.

MEC. Novo ensino médio. Dúvidas. Disponível em: http://portal.mec.gov.br/component/content/article?id=40361\#nem_01. Acesso em: 22/03/2017.

MÉSZÁROS, István. A educação para além do capital. São Paulo: Boitempo, 2005.

\begin{tabular}{|l|l|l|l|l|}
\hline Q Povista Dialectus & Ano 9 & n. 16 & Janeiro-Abril 2020 & p. $100-112$ \\
\hline
\end{tabular}


SAVIANI, Dermeval. Sistema Nacional de Educação e Plano Nacional de Educação. Campinas, SP: Autores Associados, 2014.

SAVIANI, Dermeval. Da nova LDB ao Novo Plano Nacional de Educação: por uma outra política educacional. 2. ed. rev. Campinas, SP: Autores Associados, 1998.

SAVIANI, Dermeval. Política educacional brasileira: Limites e perspectivas. Revista de Educação PUC-Campinas. Campinas, SP, n. 24, p. 7-16, junho de 2008. Disponível em: http://periodicos.puc-campinas.edu.br/seer/index.php/reveducacao/article/view/108.

Acesso em: 30/07/18.

SHIROMA, Eneida Oto; MORAES, Maria Célia Marcondes de; EVANGELISTA, Olinda. Política Educacional. 4 ed. Rio de Janeiro: Lamparina, 2011.

VIEIRA, Sofia Lerche; ALBUQUERQUE, Maria Gláucia Menezes. Política e planejamento educacional. Fortaleza: Edições Democrático Rocha, 2001.

\begin{tabular}{|l|l|l|l|l|}
\hline Q Povista Dialectus & Ano 9 & n. 16 & Janeiro-Abril 2020 & p. $100-112$ \\
\hline
\end{tabular}

